\title{
Significance of Inclusions in Electroplated Gold Films for Electronics Applications
}

\author{
Yutaka Okinaka \\ Advanced Research Center for Science and Engineering Waseda University, Tokyo, Japan \\ E-mail: okinaka@mn.waseda.ac.jp
}

Received: 15 August 2000

Minute amounts of metallic as well as non-metallic inclusions significantly affect both bulk and surface properties of the electroplated gold films being used by the electronics industry. Surface effects are caused by the presence of extraneous materials diffused out from the interior to the surface, while bulk effects are brought about by the influence of inclusions on the microstructure of the gold films. This article reviews the current status of understanding of such inclusion effects in both soft and hard gold: these play essential roles in the fabrication of today's microelectronic devices.

The physical properties of electroplated films are known to be influenced significantly by incorporated impurities or inclusions (1). Both electroplated soft and hard gold being used by the electronics industry are no exception, and inclusions determine much of bulk and surface properties of the gold films. For example, the hardness of pure, soft gold films plated from the classical cyanide bath containing $\mathrm{KAu}(\mathrm{CN})_{2}$ as the source of gold and a phosphate or citrate buffer to control $\mathrm{pH}$ is known to increase with an increase in carbon content (2). In the case of the soft gold plated from the recently developed non-cyanide bath containing sulfite and thiosulfate, the amount of included sulfur-containing species has been shown to be closely related to the hardness (3). Hardness of the soft gold used for fabricating microbumps on silicon IC chips to be mounted on circuit boards in modern electronic packaging technology, must be sufficiently low and hence easily deformable to allow uniform bonding of a large number of bumps with slightly varied thicknesses. On the other hand, hard gold is generally plated from a cyanide bath containing $\mathrm{KAu}(\mathrm{CN})_{2}$, in the presence of a citrate buffer, and a salt of cobalt, nickel, or iron as a hardening additive $(4,5)$. Hard gold is used as a contact material for electrical connectors, printed circuit boards, and relays. In these applications electrical contact resistance, the resistance to mechanical wear, and the tendency of sticking between contact surfaces are greatly affected by the presence of inclusions or extraneous materials in the bulk and/or on the surface of the gold film.
This article consists of a comprehensive review of the current status of understanding of the various effects arising from inclusions on the critical physical properties of gold deposits prepared by using recently developed as well as well-established, classical plating baths.

\section{SOFT GOLD}

Table 1 shows examples of bath compositions and operating conditions for plating soft gold. Deposits obtained from the classical cyanide bath and the noncyanide baths are discussed separately below.

\section{Classical Cyanide Bath with No Additive}

Reinheimer (2), as far back as in 1974, made a detailed study on the effects of various plating parameters on the carbon content and the hardness of gold films plated from the classical phosphate or citrate buffered cyanide bath containing no additive. He showed that from this class of baths, soft gold with a Knoop hardness lower than $c a 100 \mathrm{~kg} \mathrm{~mm}^{-2}$ can be obtained only at an elevated temperature, eg, $65^{\circ} \mathrm{C}$. He discovered that when the plating temperature was lowered below $50^{\circ} \mathrm{C}$, the hardness increased sharply, reaching a value as high as $170 \mathrm{~kg} \mathrm{~mm}^{-2}$ at $25^{\circ} \mathrm{C}$ with a concomitant increase in carbon content from below $10 \mathrm{ppm}$ in weight at $65^{\circ} \mathrm{C}$ to $850 \mathrm{ppm}$ at $25^{\circ} \mathrm{C}$. The data reported by Reinheimer are plotted in Figure 1. It 
Table 1 Examples of Basic Bath Compositions and Operating Conditions for Plating Soft Gold (additives not shown)

\section{Cyanide bath}

(4)

$\begin{array}{lc}\mathrm{KAu}(\mathrm{CN})_{2} & 0.07 \mathrm{I} \mathrm{M} \\ \mathrm{KH}_{2} \mathrm{PO}_{4} & 0.073 \\ \mathrm{~K}_{2} \mathrm{HPO}_{4} & 0.23 \\ \mathrm{Au}\left(\mathrm{SO}_{3}\right)_{2}(\text { en })^{-*} & \\ \mathrm{Na}_{2} \mathrm{EDTA}^{*} & \\ \mathrm{Na}_{2} \mathrm{SO}_{3} & \\ \text { en-sulfate* } & \\ \mathrm{NaAuCl}_{4} & \\ \mathrm{Na}_{2} \mathrm{SO}_{3} & \\ \mathrm{Na}_{2} \mathrm{~S}_{2} \mathrm{O}_{3} & \\ \mathrm{Na}_{2} \mathrm{HPO}_{4} & \\ \mathrm{pH} & \\ \text { Temperature } & \\ \text { Current density } & 7.0 \\ \text { Agitation } & 65^{\circ} \mathrm{C} \\ & 1.5-8 \mathrm{~mA} \mathrm{~cm}-2 \\ & \text { mild }\end{array}$

\author{
Sulfite bath \\ (with en*) (5)
}

Thisoulfate-sulfite

bath (3)

$\begin{array}{cc}0.04 \mathrm{M} & \\ 0.054 & \\ 0.40 & \\ 0.25 & \\ & 0.06 \mathrm{M} \\ & 0.42 \\ & 0.42 \\ & 0.30 \\ 7.0-7.5 & 6.0 \\ 60^{\circ} \mathrm{C} & 60^{\circ} \mathrm{C} \\ 5 \mathrm{~mA} \mathrm{~cm}^{-2} & 5 \mathrm{~mA} \mathrm{~cm}^{-2} \\ \mathrm{mild}^{2} & \mathrm{mild}\end{array}$

$*$ en $=$ ethylenediamine

is remarkable that the high hardness found at $25^{\circ} \mathrm{C}$ is nearly equal to that of the conventional hard gold plated from a Co- or Ni-containing bath. Based on this finding, the process for plating the so-called additive-free hard gold (AFHG) was developed subsequently, and the gold deposit obtained by this process was evaluated extensively for practical applications $(6,7)$.

The existence of a close relationship between hardness and carbon content of the soft gold from the cyanide bath is more clearly seen from the plot shown in Figure 2. The data used to obtain this graph were taken from Reinheimer (2). It is remarkable that in spite of the fact that the gold films analysed to obtain these data were prepared by varying three different plating parameters, $i e$, temperature, $\mathrm{pH}$, and current density, all data points fell on a single line. This result shows that the carbon content is indeed the common factor causing the variation of hardness.

Reinheimer (2) expended a considerable effort to chemically identify the carbon-containing species. The only carbon-containing species present in the freshly prepared plating bath is $\mathrm{Au}(\mathrm{CN})_{2}^{-}$, which produces free $\mathrm{CN}^{-}$and $\mathrm{HCN}$ during plating. It is known that a large number of organic compounds can be derived from the latter two species. Examples cited by Reinheimer include formamide $\left(\mathrm{HCONH}_{2}\right)$, diaminomaleonitrile (tetramer of $\mathrm{HCN},(\mathrm{HCN})_{4}$ ), $\mathrm{CN}$-polymer, and oxiamide $\left(\mathrm{CO}\left(\mathrm{NH}_{2}\right)_{2}\right)$. He made a systematic investigation of effects of the addition of each of these compounds into the plating bath on the carbon content and the morphology of the resulting gold deposits, but none of the compounds tested was found to cause an increase in carbon content.

The only carbon-containing species that has positively been identified in the gold plated from additive-free baths is $\mathrm{AuCN}$, which is an intermediate species proposed to form during the reduction of $\mathrm{Au}(\mathrm{CN})_{2}^{-}$to $\mathrm{Au}(8-10)$. A transmission electron microscope (TEM) investigation (11) showed that non-metallic objects measuring 2 to $20 \mathrm{~nm}$ are distributed in AFHG in a manner similar to that observed with $\mathrm{CoHG}$, which is shown in the subsequent section, and that thermal ageing of the gold at $150^{\circ} \mathrm{C}$ for 1 week produced crystals of $\mathrm{AuCN}$ on the gold surface. Holmbom and Jacobson (12) observed, also by TEM, the presence of AuCN crystals at grain boundaries in a gold deposit plated from a citrate buffered plating solution operated at $40^{\circ} \mathrm{C}$. More recently, Sawaguchi et al (13) identified the formation of $\mathrm{AuCN}$ adlayer on the surface of a single crystal of $\mathrm{Au}(111)$ by means of scanning tunneling microscopy (STM).

From the results described above, it is concluded that the source of carbon included in the gold plated from additive-free cyanide baths is $\mathrm{AuCN}$, and that this species in the adsorbed state inhibits the growth of gold crystals and hence promotes nucleation. The fine grained deposit thus formed is expected to possess an increased hardness based on the well-known HallPetch relationship between hardness and grain size. 


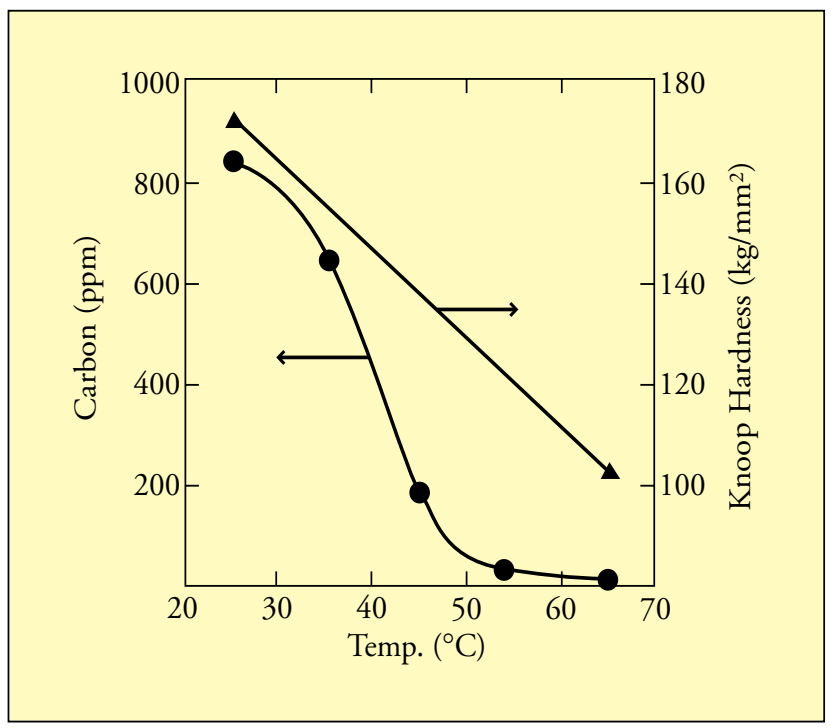

Figure 1 Effect of plating temperature on carbon content and hardness of gold films plated from phosphate-buffered additive-free cyanide bath (from reference 2)

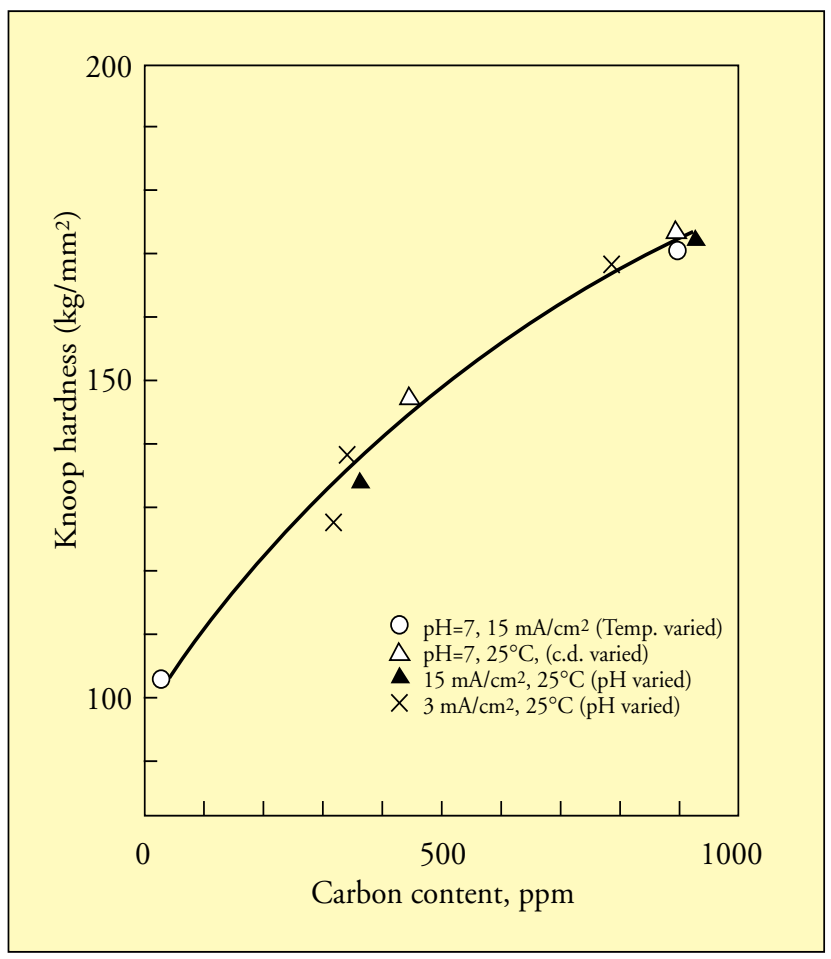

Figure 2 Relationship between carbon content and hardness of gold films plated from phosphate-buffered additivefree cyanide bath (Data taken from reference 2)

\section{Classical Cyanide Bath with Additive}

It is customary to add a trace amount of $\mathrm{Tl}^{+}(14), \mathrm{Pb}^{2+}$ $(15)$, or $\mathrm{As}^{3+}(16,17)$ in the cyanide bath, since this makes it possible to obtain brighter gold deposits over a wider current density range than can be obtained in the absence of the additive. The additives are often called "grain refiners", but this term is misleading because the reasons why these additives make the appearance of the gold surface bright are different for $\mathrm{Tl}^{+}$and $\mathrm{Pb}^{2+}$ on one hand and for $\mathrm{As}^{3+}$ on the other. The effect of $\mathrm{Tl}^{+}$or $\mathrm{Pb}^{2+}$ is to yield gold crystals with well-developed facets, which make the gold surface bright, whereas the addition of $\mathrm{As}^{3+}$ has indeed been shown to decrease the grain size to only one fifth of that obtained in its absence (18), which also causes brightening. Because of the decrease in grain size, the addition of $\mathrm{As}^{3+}$ is known to increase the hardness (19). McIntyre and Peck (9) found that the addition of $\mathrm{Tl}^{+}$or $\mathrm{Pb}^{2+}$ induces depolarization of the gold deposition potential through the catalytic effect of an adsorbed monolayer of $\mathrm{Tl}$ or $\mathrm{Pb}$, whereas no such depolarization or electrocatalytic effect was observed with the addition of $\mathrm{As}^{3+}$.

One common feature of the three additives is that they all co-deposit with the gold and, under uncontrolled conditions, adversely affect the bond strength when an aluminium or gold wire is bonded to the plated gold $(20,21)$. This adverse effect becomes more pronounced at higher additive concentrations, at higher plating current densities, and upon baking the gold deposit. Endicott et al (20) compared bond strengths of $\mathrm{Al}$ wire to the gold deposits plated from baths containing the three different additives, and found that the highest bond strength was obtained with $\mathrm{As}^{3+}$ as the additive. With any one of the additives, it is important to control the concentration of the additive element included in the gold deposit at a low level, eg, lower than $50 \mathrm{ppm}$, to avoid bond failure (21). These aspects were investigated extensively in the past, and the results are well documented (20 23). The interested reader is also referred to the review articles published previously by this author $(24,25)$ for more detailed descriptions.

\section{Non-Cyanide Batbs}

Gold plating on microelectronic devices and circuit boards are often carried out through patterns defined by photolithography. Because the conventional positive photoresist used for this purpose is attacked by cyanide ions, a non-cyanide bath, especially the one containing gold in the form of $\mathrm{Au}(\mathrm{I})$-sulfite complex, is now widely used in place of the cyanide bath. However, the stability of $\mathrm{Au}(\mathrm{I})$ sulfite complex is orders of magnitude smaller $\left(\mathrm{K}=10^{10}\right)$ than that of $\mathrm{Au}(\mathrm{I})$ cyanide complex $\left(\mathrm{K}=10^{39}\right)$, and consequently a solution of $\mathrm{Au}(\mathrm{I})$ sulfite complex tends to undergo a disproportionation reaction, $3 \mathrm{Au}^{+} \rightarrow \mathrm{Au}^{3+}+2 \mathrm{Au}$, which leads to bath decomposition with the formation 
of metallic gold. To suppress this reaction, organic additives and/or complexing agents are added to the bath. An example of the sulfite bath is included in Table 1 for comparison.

The possibility of plating gold from $\mathrm{Au}(\mathrm{I})$ thiosulfate complex has long been known $(5,26)$, but it has never been used for making a practical electroplating bath. The stability constant of $\mathrm{Au}\left(\mathrm{S}_{2} \mathrm{O}_{3}\right)_{2}{ }^{3-}$ complex ion is equal to $10^{29}$, which is substantially greater than that of the corresponding sulfite complex, $10^{10}$. Thus, the thiosulfate complex might be expected to be a viable alternative to the sulfite complex. The reason why the thiosulfate complex has not been used successfully for making a practical gold plating bath seems to be the instability of the thiosulfate ion itself with respect to the reaction: $\mathrm{S}_{2} \mathrm{O}_{3}{ }^{2-} \leftrightarrow \mathrm{S}+\mathrm{SO}_{3}{ }^{2-}$.

As the above equilibrium reaction suggests, the addition of excess sulfite is expected to stabilize the thiosulfate ion. As a matter of fact, electroless gold plating baths containing both thiosulfate and sulfite were developed successfully some years ago (27 - 30). As a natural extention of that development, the author and co-workers employed the same mixed ligand system to formulate an electroplating bath (3). This system is highly stable, and no stabilizer needs to be added. A basic composition of the mixed ligand bath is shown in Table 1. One anticipated application of this bath is for the fabrication of arrays of microbumps on silicon chips. The gold deposit to be used for this purpose must be as soft as possible for the reason mentioned in the introduction to this article. Therefore, an extensive investigation was carried out to understand factors affecting the deposit hardness. It was found that a sulfur-containing inclusion greatly influences the hardness (3), and the results of this and more recent studies are summarized below.

In the initial study of gold deposition from the mixed ligand system, five variables were found to affect the hardness as well as the sulfur content of the deposit. They are current density, bath temperature, $\mathrm{pH}$, the addition of thallium ions, and the total ligand concentration $\left(\left[\mathrm{S}_{2} \mathrm{O}_{3}{ }^{2-}\right]+\left[\mathrm{SO}_{3}{ }^{2-}\right]\right)$. Figure 3 shows that both hardness and sulfur content decrease with increasing total ligand concentration, where the ratio of $\left[\mathrm{S}_{2} \mathrm{O}_{3}{ }^{2-}\right]$ to $\left[\mathrm{SO}_{3}{ }^{2-}\right]$ was kept constant at unity. Plotting the hardness data in this figure against the sulfur content yields the upper curve (curve 1) in Figure 4. The lower curve (curve 2) shows the hardness-sulfur content relationship found with the addition of various concentrations of $\mathrm{Tl}^{+}$in the bath. Both curves show that the hardness increases with increasing sulfur content, but it should be noted that effects of the two variables on the relationship between sulfur content and hardness are different from each other. Clearly, this difference indicates that sulfur content is not the only factor affecting the hardness.

The effect of $\mathrm{Tl}^{+}$in the mixed ligand system is similar to that known for the classical cyanide system. Namely, it serves as a depolarizer for the cathodic gold deposition reaction, and it promotes the formation of well-developed crystals (3), and this appears to counteract the effect of sulfur inclusion on hardness. This effect accounts for the result indicated in Figure 4 that the hardness value observed with the addition of $\mathrm{Tl}^{+}$is lower than that found without $\mathrm{Tl}^{+}$at any specific value of sulfur content. It should be mentioned that thallium is incorporated into the gold, as in the case of the cyanide system, and therefore caution should be exercised to maintain the thallium content of the deposit below the specific level described in the preceding section to avoid adverse effects on the bond strength.

The decrease in sulfur content observed with increasing total ligand concentration shown in Figure 3 was rather unexpected, and hence a detailed study was conducted to establish the mechanism of sulfur inclusion and to identify the sulfur-containing species included in the gold (31). The first series of experiments was carried out to determine whether the included sulfur comes from sulfite or thiosulfate or both. For this purpose gold deposits obtained from three different baths containing, as ligands, sulfite alone, thiosulfate alone, and both sulfite and

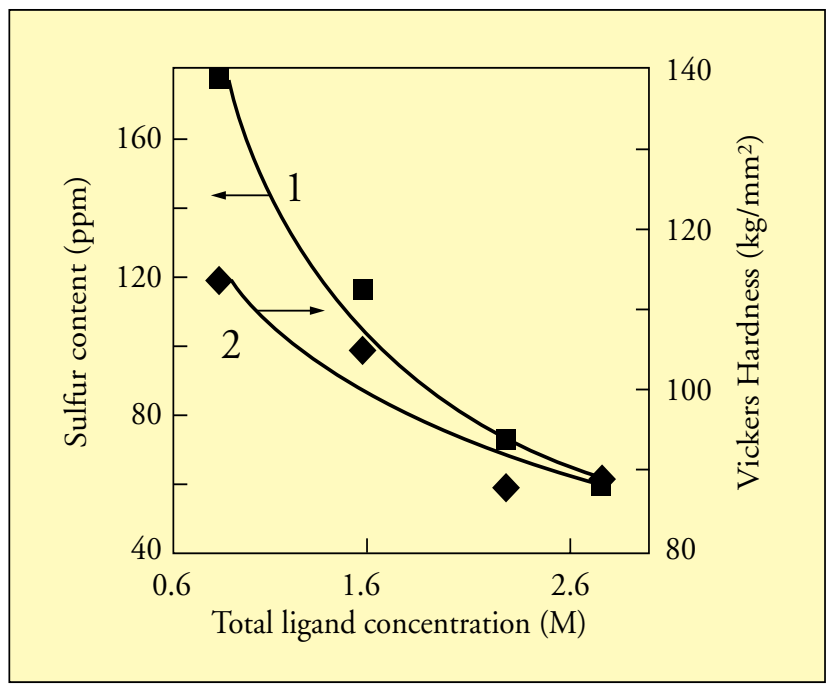

Figure 3 Effect of total ligand concentration $\left(\left[\mathrm{S}_{2} \mathrm{O}_{3}{ }^{2-}\right]+\right.$ $\left[\mathrm{SO}_{3}{ }^{2-}\right]$ ) on sulfur content and hardness of gold deposit plated from thiosulfate-sulfite bath $\left(\left[\mathrm{S}_{2} \mathrm{O}_{3}{ }^{2-}\right]=\right.$ $\left[\mathrm{SO}_{3}{ }^{2-}\right]$ ) (from reference 3) 


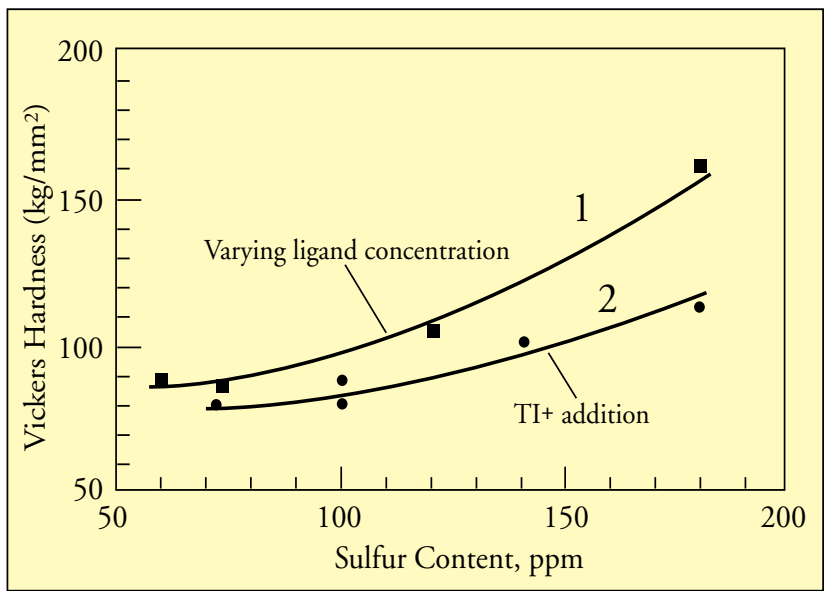

Figure 4 Relationship between sulfur content and hardness of gold films plated from thiosulfate-sulfite bath (Data taken from reference 3)

thiosulfate were analysed for sulfur. Other experimental conditions are as listed in Table 1 and are identical for the three baths. The sulfur contents of the gold deposits obtained from the three baths were 40, 190 , and $110 \mathrm{ppm}$, respectively. These results revealed that the included sulfur results from both sulfite and thiosulfate, but the latter is the predominant source of sulfur. This conclusion is in accord with the result of an electrochemical study of electroless gold deposition from the mixed ligand system $(28-30)$ that the gold deposition takes place primarily from the thiosulfate complex, $\left[\mathrm{Au}\left(\mathrm{S}_{2} \mathrm{O}_{3}\right)_{2}\right]^{3-}$, rather than from the sulfite complex, $\left[\mathrm{Au}\left(\mathrm{SO}_{3}\right)_{2}\right]^{3-}$, as expected from the fact that the stability constant of the former is much greater than that of the latter as already mentioned. Under certain conditions, the mixed ligand complex, $\left[\mathrm{Au}\left(\mathrm{S}_{2} \mathrm{O}_{3}\right)\left(\mathrm{SO}_{3}\right)\right]^{3-}$, also appears to participate in the reaction (28), but as a first approximation, participation of the mixed ligand complex will not be considered here.

The following two forms of sulfur inclusion were considered:

1 Elemental sulfur formed by one of the following two reactions: (a) $\mathrm{S}_{2} \mathrm{O}_{3}{ }^{2-} \leftrightarrow \mathrm{S}+\mathrm{SO}_{3}{ }^{2-}$, or

(b) $\mathrm{S}_{2} \mathrm{O}_{3}{ }^{2-}+6 \mathrm{H}++4 \mathrm{e}^{-} \leftrightarrow 2 \mathrm{~S}+3 \mathrm{H}_{2} \mathrm{O}$.

2 A thiosulfate compound:
(a) $\mathrm{NaAu}\left(\mathrm{S}_{2} \mathrm{O}_{3}\right)$, or
(b) $\mathrm{Au}_{2} \mathrm{~S}_{2} \mathrm{O}_{3}$.

The distinction between 1 and 2 was made by comparing the results of sulfur analyses performed by a combustion method in an oxygen atmosphere or a nitrogen atmosphere. Because the method measures sulfur in the form of $\mathrm{SO}_{2}$ produced by combustion of the sample, elemental sulfur can be determined only in an atmosphere containing oxygen and not in pure nitrogen. Experimentally, identical results were found in both pure oxygen and pure nitrogen: 110 and 115 ppm for deposits plated in the mixed ligand bath, and 180 and $190 \mathrm{ppm}$ for deposits produced in the bath containing thiosulfate alone. Based on these results, it was concluded that elemental sulfur is not the form of sulfur included in the gold. The two forms of thiosulfate compounds (a) and (b) indicated in 2 above were then considered. The compound (a) is known to be a slightly soluble compound (32). If this compound is the only source of sulfur, $\mathrm{Na}$ should be present in the gold, and the atomic ratio of $\mathrm{Na}$ to $\mathrm{S}$ should be equal to $0.5: 1$. Experimentally, the atomic ratio was found to be as small as 0.14:1. If it is assumed that the entire amount of $\mathrm{Na}$ found comes from this compound, $\mathrm{NaAu}\left(\mathrm{S}_{2} \mathrm{O}_{3}\right)$, this result shows that this insoluble salt accounts for only $14 \%$ of the entire quantity of sulfur included in the gold. Based on the above arguments, it is thought reasonable to assume that a major portion of included sulfur is present in the form of $\mathrm{Au}_{2} \mathrm{~S}_{2} \mathrm{O}_{3}$. This species is likely to be in an adsorbed state on the cathode surface according to equation (1) :

$$
\begin{gathered}
2\left[\mathrm{Au}\left(\mathrm{S}_{2} \mathrm{O}_{3}\right)_{2}\right]^{3-} \leftrightarrow\left(\mathrm{Au}_{2} \mathrm{~S}_{2} \mathrm{O}_{3}\right)_{\mathrm{ads}}+3 \mathrm{~S}_{2} \mathrm{O}_{3}{ }^{2-} \\
\left(\mathrm{Au}_{2} \mathrm{~S}_{2} \mathrm{O}_{3}\right)_{\mathrm{ads}}+2 \mathrm{e}^{-} \rightarrow 2 \mathrm{Au}+\mathrm{S}_{2} \mathrm{O}_{3}{ }^{2-} \\
{\left[\mathrm{Au}\left(\mathrm{S}_{2} \mathrm{O}_{3}\right)_{2}\right]^{3-}+\mathrm{e}^{-} \rightarrow \mathrm{Au}+2 \mathrm{~S}_{2} \mathrm{O}_{3}{ }^{2-}}
\end{gathered}
$$

Reaction (1) can be followed by the electrochemical reduction (2) of $\left(\mathrm{Au}_{2} \mathrm{~S}_{2} \mathrm{O}_{3}\right)_{\text {ads }}$ to deposit gold with the overall reaction given by (3). Reaction (1) indicates that the formation of the adsorbed species, and hence the sulfur inclusion, is more favoured at lower free $\mathrm{S}_{2} \mathrm{O}_{3}{ }^{2-}$ concentrations. At high $\mathrm{S}_{2} \mathrm{O}_{3}{ }^{2-}$ concentrations the gold deposition is believed to take place directly from the bulk species, $\left[\mathrm{Au}\left(\mathrm{S}_{2} \mathrm{O}_{3}\right)_{2}\right]^{3-}$, without going through the formation of the adsorbed intermediate. Thus, the above mechanism explains the experimental result that the smaller amount of sulfur is included in the gold at higher free thiosulfate concentrations. This mechanism is similar to that of the reduction of $\mathrm{Au}(\mathrm{CN})_{2}^{-}$, in which $(\mathrm{AuCN})_{\mathrm{ads}}$ is formed as an intermediate $(8-10)$, as described in the preceding section.

In the gold deposit plated from the cyanide bath, AuCN was actually observed by TEM $(11,12)$. An attempt was made to observe the sulfur-containing inclusion in the gold deposited from the thiosulfatesulfite bath using high resolution TEM. However, no inclusion was detected with a specimen containing 120 ppm $S$ even at the highest magnification employed, 
which was $1,292 \mathrm{KX}$ (33). The probable reason for the difference in TEM detectability between $\mathrm{AuCN}$ and $\mathrm{Au}_{2} \mathrm{~S}_{2} \mathrm{O}_{3}$ is that at least a portion of $\mathrm{AuCN}$ exists in the form of a polymeric crystal with a size observable by TEM, whereas $\mathrm{Au}_{2} \mathrm{~S}_{2} \mathrm{O}_{3}$ does not form such a polymeric species. Furthermore, a quartz crystal microbalance (QCM) study was carried out, which showed a clear weight gain of the gold-coated crystal due to the formation of an adsorbed species in the mixed ligand system (31). Further details will be reported in a separate communication.

It should be mentioned in passing that the minimum hardness of the gold plated from the mixed ligand bath in an as-deposited state is approximately $80-90 \mathrm{~kg} \mathrm{~mm}^{-2}$ in Vickers hardness number with a sulfur content of 70-80 ppm. This hardness can be lowered to approximately $50 \mathrm{~kg} \mathrm{~mm}^{-2}$ by annealing at $350^{\circ} \mathrm{C}$ for $30 \mathrm{~min}$ (3), which indicates that grain growth occurs readily at this temperature in spite of the presence of the inclusion.

\section{HARD GOLD}

Three different kinds of hard gold are discussed in this section: cobalt-hardened gold (CoHG), nickelhardened gold (NiHG), and additive-free hard gold (AFHG). Typical bath compositions and operating conditions are given in Table 2. Much of the knowledge presently available on hard gold was acquired by extensive investigations of $\mathrm{CoHG}$, and therefore the discussion presented below will be heavily inclined toward CoHG. However, NiHG and AFHG do find specific applications because of their unique properties, and hence a brief discussion of those two

Table 2 Examples of Bath Compositions and Operating Conditions for Plating Hard Gold

\begin{tabular}{|c|c|c|}
\hline & $\begin{array}{c}\text { CoHG or NiHG } \\
\text { bath }(37)\end{array}$ & $\begin{array}{c}\text { AFHG bath } \\
(6)\end{array}$ \\
\hline $\begin{array}{l}\mathrm{KAu}(\mathrm{CN})_{2} \\
\text { Citric acid } \\
\mathrm{KOH} \\
\mathrm{CoSO}_{4} \text { or } \mathrm{NiSO}_{4}\end{array}$ & $\begin{array}{c}0.04 \mathrm{M} \\
0.52 \\
0.89 \\
0.008\end{array}$ & \\
\hline $\begin{array}{l}\mathrm{KAu}(\mathrm{CN})_{2} \\
\mathrm{KH}_{2} \mathrm{PO}_{4}\end{array}$ & & $\begin{array}{c}0.14 M \\
0.73\end{array}$ \\
\hline $\begin{array}{l}\mathrm{pH} \\
\text { Temperature } \\
\text { Current density } \\
\text { Agitation }\end{array}$ & $\begin{array}{c}4.0 \\
30^{\circ} \mathrm{C} \\
10 \mathrm{~mA} \mathrm{~cm}^{-2} \\
\text { mild }\end{array}$ & $\begin{array}{c}4.3-4.5 \\
25^{\circ} \mathrm{C} \\
10-20 \mathrm{~mA} \mathrm{~cm}-2 \\
\text { mild }\end{array}$ \\
\hline
\end{tabular}

types of hard gold will also be included.

The CoHG contains less than $0.4 \mathrm{wt} \%$ of $\mathrm{Co}$, and yet its hardness is as high as $170-200 \mathrm{~kg} \mathrm{~mm}^{-2}$ in Knoop hardness compared to $50-80 \mathrm{~kg} \mathrm{~mm}^{-2}$ for soft gold. The high hardness of $\mathrm{CoHG}$ cannot be reproduced by simple metallurgical dissolution or alloying of such a small amount of metallic Co in pure gold metal. A detailed study of the hardening mechanism, performed by Lo et al (34), showed that the major factor determining the hardness is the grain size. The CoHG deposit consists of extremely small grains measuring 20-30 nm, compared to $1-2 \mu \mathrm{m}$ for soft gold (35). The presence of a significant amount of impurities or inclusions is believed to be responsible for the decrease in grain size, because impurities, especially if present in an adsorbed state on the surface of growing gold crystals, can inhibit the growth of crystal grains and hence promote the formation of new nuclei during gold plating when it is carried out at a constant current density.

\section{Analysis, Identification, and Observation of Inclusions}

Historically, the presence of a significant quantity of carbon-containing material within $\mathrm{CoHG}$ was discovered by Munier (36) during her investigation of the cause of an increase in the electrical contact resistance occasionally observed in telephone switching equipment. Systematic studies carried out later by Raub and co-workers (37) conclusively indicated the inclusion of significant amounts of other elements such as $\mathrm{H}, \mathrm{O}, \mathrm{N}$, and $\mathrm{K}$ in addition to $\mathrm{C}$. As an example, a list of concentrations of those impurity elements found in a sample of $\mathrm{CoHG}$ is given in Table 3 together with that for AFHG.

Table 3 Included Elements in Hard Gold Deposits

\begin{tabular}{lcccc} 
& \multicolumn{2}{c}{ CoHG (37) } & \multicolumn{2}{c}{ AFHG (6) } \\
& wt\% & at\% & wt\% & at\% \\
Co & 0.20 & 0.57 & - & - \\
$\mathrm{C}$ & 0.28 & 3.93 & 0.055 & 0.88 \\
$\mathrm{H}$ & 0.041 & 6.90 & 0.001 & 0.19 \\
$\mathrm{O}$ & 0.092 & 0.97 & 0 & 0 \\
$\mathrm{~N}$ & 0.16 & 1.92 & 0.03 & 0.41 \\
$\mathrm{~K}$ & 0.28 & 1.20 & 0.22 & 1.08 \\
Total & 1.05 & 15.5 & 0.31 & 2.56 \\
Purity as Au & 98.9 & 84.5 & 99.7 & 97.4
\end{tabular}


The first attempt to visually observe the inclusions in CoHG was made by Munier (36), who dissolved under an optical miscroscope a small piece of thin CoHG film in the vapour of aqua regia and found polymer-like films remaining after dissolution of the gold. These films were collected and analysed for carbon as well as cobalt. Munier reported that a significant amount of carbon was found in the residue but no cobalt was detected. Thus, the residue was thought to be an organic polymer derived from cyanide species. On the contrary, a subsequent analysis of a more macroscopic amount of the residue collected by dissolving a large quantity of $\mathrm{CoHG}$ in aqua regia showed conclusively that the residue is a $\mathrm{Co}-\mathrm{CN}$ compound containing cobalt in both divalent and trivalent forms: $\mathrm{Co}_{3}{ }_{3}\left[\mathrm{Co}^{\mathrm{III}}(\mathrm{CN})_{6}\right]_{2} \cdot \mathrm{xH}_{2} \mathrm{O}$ (38). It was conjectured that this residue is a product of combination of $\mathrm{Co}^{2+}$ ions formed upon dissolution of metallic Co in the gold with $\left[\mathrm{Co}^{\mathrm{III}}(\mathrm{CN})_{6}\right]^{3-}$ that is either present in the gold or formed upon its dissolution. As a matter of fact, chemical analysis of the residue formed upon dissolution of $\mathrm{CoHG}$ in mercury showed the presence of $\mathrm{K}_{3} \mathrm{Co}(\mathrm{CN})_{6}$. It should be noted, however, that this analytical result does not unequivocally prove that the non-metallic cobalt exists in the trivalent form. The divalent cobalt cyanide complex anion, $\left[\mathrm{Co}^{\mathrm{II}}(\mathrm{CN})_{5}\right]^{3-}$, is known to be unstable and in the presence of excess $\mathrm{CN}^{-}$and water it forms the corresponding trivalent complex (39):

$$
\begin{gathered}
2\left[\mathrm{Co}^{\mathrm{II}}(\mathrm{CN})_{5}\right]^{3-}+2 \mathrm{CN}^{-}+2 \mathrm{H}_{2} \mathrm{O} \rightarrow 2\left[\mathrm{Co}^{\mathrm{III}}(\mathrm{CN})_{6}\right]^{3-} \\
+2 \mathrm{OH}^{-}+\mathrm{H}_{2}
\end{gathered}
$$

Nevertheless, the possibility of the divalent Co complex being the species included in the gold cannot be dismissed, as pointed out by Kahn (40).

Direct observation of inclusions in CoHG using TEM was made by Nakahara $(35,41)$ and Fluehmann et al (42). It was found that CoHG contains a large number $\left(10^{19} \mathrm{~cm}^{-3}\right)$ of "phase objects" measuring 0.5 $7.0 \mathrm{~nm}$ in diameter distributed uniformly. (The "phase objects" are so called because their images result from objects causing phase shift, rather than ordinary diffraction, of transmitted electron beams.) The phase objects can be non-metallic solid materials, gas bubbles, or voids (41). A TEM photograph demonstrating the distribution of phase objects in CoHG is shown in Figure 5, in which the phase objects are seen as small dark spots. The observed inclusion has not been directly identified with regard to chemical composition. A portion of it appears to be $\mathrm{AuCN}$, which has been shown to exist in $\mathrm{CoHG}$ as well as in AFHG by Nakahara (43). Thus, the Co(II)and/or $\mathrm{Co}(\mathrm{III})-\mathrm{CN}$ compound and $\mathrm{AuCN}$ at least partly account for the carbon content of CoHG. It should be noted here that if those cyanide compounds are the only source of carbon in the gold, the atomic ratio of $\mathrm{C} / \mathrm{N}$ should be equal to unity. Experimentally, however, this ratio was always found to be in the range of approximately 1.6 to 2.1 (37), as seen in the example given in Table 3. The presence of the large excess $\mathrm{C}$ over $\mathrm{N}$ indicates that additional carboncontaining compound(s) appear to exist in CoHG.

In addition to carbon-containing compounds, it is possible that the phase objects in the TEM image include gas bubbles or voids. It is of interest to note in Table 3 that in $\mathrm{CoHG}$ the relative quantity of hydrogen as an element is large in terms of atomic per cent compared to the amounts of other included elements. Therefore, special attention was paid to finding in what form(s) the hydrogen exists in CoHG. The mass spectrometric analysis of gases evolved upon heating CoHG up to $1000^{\circ} \mathrm{C}$, performed by Gallagher (44), detected the evolution of the following: $\mathrm{H}_{2}$, $\mathrm{H}_{2} \mathrm{O}, \mathrm{HCN}, \mathrm{NH}_{3},(\mathrm{CN})_{2}, \mathrm{~N}_{2}$ and/or $\mathrm{CO}$, and $\mathrm{CO}_{2}$, the first four of which contain hydrogen atoms. Some of these compounds are obviously products of thermal decomposition of other occluded compounds, whereas hydrogen could be present in the form of gas bubbles or in voids, as it is known that gold does not dissolve hydrogen in its lattice. It should be remembered that the current efficiency for the electrochemical deposition of CoHG is less than $40 \%$, the remainder of current being accounted for by hydrogen gas

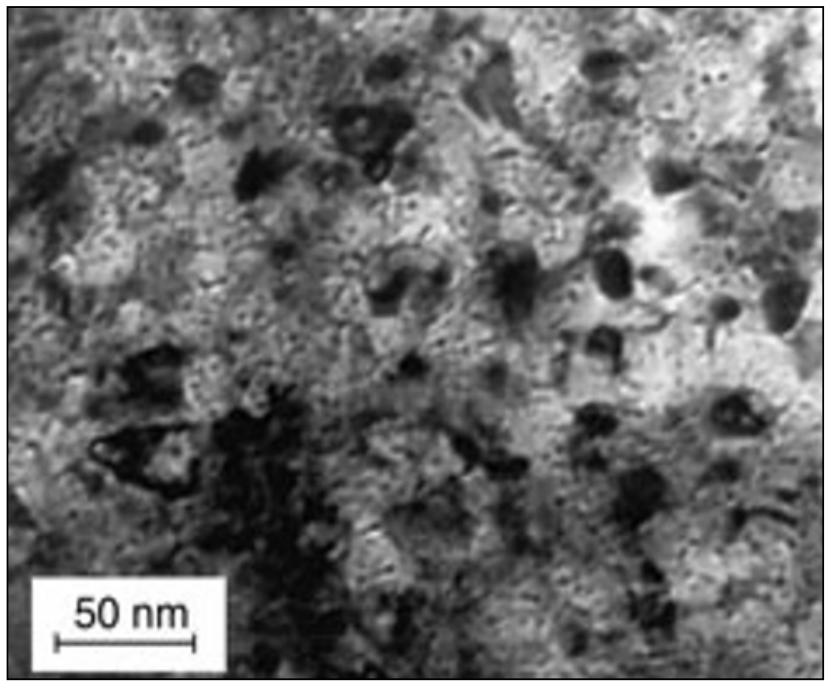

Figure 5 Transmission electron micrograph of cobalt-hardened gold film (taken by Nakahara, Lucent Technologies) (Numerous tiny dark spots are images of inclusions. Original magnification, 400,000X) 
evolution. Thus, entrapment of a small portion of the hydrogen gas can be expected. The possibility of the inclusion of hydrogen and its effects on physical properties of hard gold was pointed out earlier by Raub $(37,45)$. More recently, Cavallotti and his co-workers $(46,47)$ performed an investigation of hydrogen effects in the electrodeposition and electroforming of $\mathrm{Au}, \mathrm{Cu}$, and $\mathrm{Au}-\mathrm{Cu}$ alloy.

We carried out analysis of hydrogen in CoHG using a fusion method with a thermal conductivity monitor, in which the temperature was scanned slowly up to $1000^{\circ} \mathrm{C}$ and the output signal recorded as a function of temperature (48). This experiment revealed that gaseous hydrogen evolved in three separated temperature ranges with peaks at $500^{\circ}, 620^{\circ}$, and $750^{\circ} \mathrm{C}$, and that the last peak was the sharpest and the highest. In his mass spectrometric analysis, Gallagher observed that the evolution of hydrogen occurred only in the temperature range of $300^{\circ}$ to $500^{\circ} \mathrm{C}$ with a single peak at $400^{\circ}$ to $450^{\circ} \mathrm{C}$ (44). To find the cause of the difference between Gallagher's results and ours, it was thought desirable to measure directly only molecular hydrogen existing in $\mathrm{CoHG}$ without possible interference from hydrogen molecules produced by thermal decomposition of other included compound(s). Previously, Graebner and Okinaka (49) succeeded in directly determining molecular hydrogen existing in electroless copper deposits by using a technique called low temperature calorimetry. This technique utilizes the fact that molecular hydrogen consists of $75 \%$ orthohydrogen and $25 \%$ of para-hydrogen at room temperature, and that when this mixture is quenched to $0^{\circ} \mathrm{K}$, all the ortho- $\mathrm{H}_{2}$ is converted to para- $\mathrm{H}_{2}$. This conversion is known to be a slow exothermic reaction, and measuring the heat generated by this reaction after quickly lowering the temperature to $0^{\circ} \mathrm{K}$ (the actual experiment was performed using liquid helium at $4^{\circ} \mathrm{K}$ ) allowed the determination of $\mathrm{H}_{2}$ molecules in electroless copper deposits. Application of the same technique to CoHG was considered, but unfortunately the method was found to be inapplicable to samples containing a magnetic material such as cobalt or nickel.

Another known method of selective analysis for hydrogen in solids is neutron scattering spectrometry. A possibility of the application of this method to the analysis of hydrogen in hard gold was suggested by Raub (50). The method is based on the fact that when an $\mathrm{H}_{2}$-containing sample is exposed to a neutron beam at a temperature near $0^{\circ} \mathrm{K}$, its magnetic moment causes transformation of the para- $\mathrm{H}_{2}$ back into ortho- $\mathrm{H}_{2}$, which results in inelastic scattering of neutrons, and that measurement of the intensity of the scattered neutrons allows determination of $\mathrm{H}_{2}$ in the sample. We submitted 25g of a CoHG sample to the Japan Atomic Energy Research Institute, where the experiment was performed at $10^{\circ} \mathrm{K}$ with an incident neutron density of $10^{8}$ $\mathrm{cm}^{-2} \mathrm{sec}^{-1}$. The result was that the scattering signal at 14 $\mathrm{meV}$ expected for $\mathrm{H}_{2}$ was not observed. Detailed analysis of this result led us to conclude that the calculated detection limit under the experimental conditions used was $11 \mathrm{mmol}$ as $\mathrm{H}_{2}$, whereas the $\mathrm{CoHG}$ sample submitted contained a maximum of only $1.4 \mathrm{mmol}$ as estimated from the result of fusion analysis (48). Thus, the experiment would have had to be repeated with a much greater quantity of a CoHG sample, eg, 150g, which actually could not be handled by the neutron experimental set-up available without major modifications.

In spite of the negative result of our attempt to determine $\mathrm{H}_{2}$ directly, the results of fusion analysis in combination with those of mass spectrometric analysis show beyond doubt that molecular $\mathrm{H}_{2}$ does exist in CoHG. We estimated that the internal pressure of $\mathrm{H}_{2}$ in $\mathrm{CoHG}$ can be as high as $250 \mathrm{~atm}$ at $25^{\circ} \mathrm{C}$ (48). This value was derived from the void volume of $9.3 \%$ calculated from the known specific gravity of $\mathrm{CoHG}$, which is of the order of $17.5 \mathrm{~g} \mathrm{~cm}^{-3}$ as compared to $19.3 \mathrm{~g} \mathrm{~cm}^{-3}$ for pure gold, and the amount of $\mathrm{H}_{2}$ of $109 \mathrm{ppm}$ estimated from the first peak obtained by the fusion analysis.

\section{Effects of Inclusions on Physical Properties}

As was mentioned already, the high hardness of hard gold is mostly due to the small grain size, which in turn results from the inhibition of grain growth brought about by the adsorption of included species on the surface of growing crystal grains. The high hardness is undoubtedly an important attribute, but other properties are equally or even more important for practical applications. For electrical connectors and circuit board contacts, the properties required are (i) low electrical contact resistance and (ii) high resistance to mechanical wear, and additionally for relay contacts, (iii) an absence of premature failure due to sticking of two contact surfaces. All of these properties are influenced greatly by inclusions. Recently this author reviewed those issues in detail elsewhere $(48,51)$, and therefore only very brief descriptions will be given below.

\section{(i) Electrical Contact Resistance}

The contact resistance of $\mathrm{CoHG}$ increases to an unacceptable level when it is exposed to an elevated temperature. This phenomenon occurs especially severely when the metallic cobalt content of the gold is 
high, because the increased contact resistance is a result of the formation of $\mathrm{CoO}$ on the surface, which is produced upon thermal oxidation of metallic $\mathrm{Co}$, and not by the Co-CN complex included in the gold (52, 53).

Compared to CoHG, the contact resistance of $\mathrm{NiHG}$ is known to be significantly more stable at elevated temperatures $(54,55)$. The cause of this difference between CoHG and NiHG has not been clarified, to the author's knowledge.

The AFHG was originally developed to provide a solution to the problem of contact resistance instability of $\mathrm{CoHG}(6,7)$. Experimentally, it was shown that the contact resistance of AFHG is indeed more stable than that of CoHG. However, under severe thermal ageing conditions, even AFHG showed a significant increase in contact resistance (7), indicating that the elimination of cobalt in the gold does not provide a complete solution to the problem. This phenomenon was attributed to surface segregation of $\mathrm{AuCN}$ included in AFHG (6). Because AuCN is also present in CoHG (43), it is likely that the increase in contact resistance of $\mathrm{CoHG}$ brought about by thermal ageing is also partly due to surface segregation of $\mathrm{AuCN}$.

\section{(ii) Resistance to Mechanical Wear}

The CoHG containing suitable amounts of metallic $\mathrm{Co}$ and $\mathrm{CN}$-complexed $\mathrm{Co}$ at a ratio within a specific range (53) exhibits excellent resistance to wear, even without applying any lubricating material, when it is subjected to repetitive sliding motion under an applied

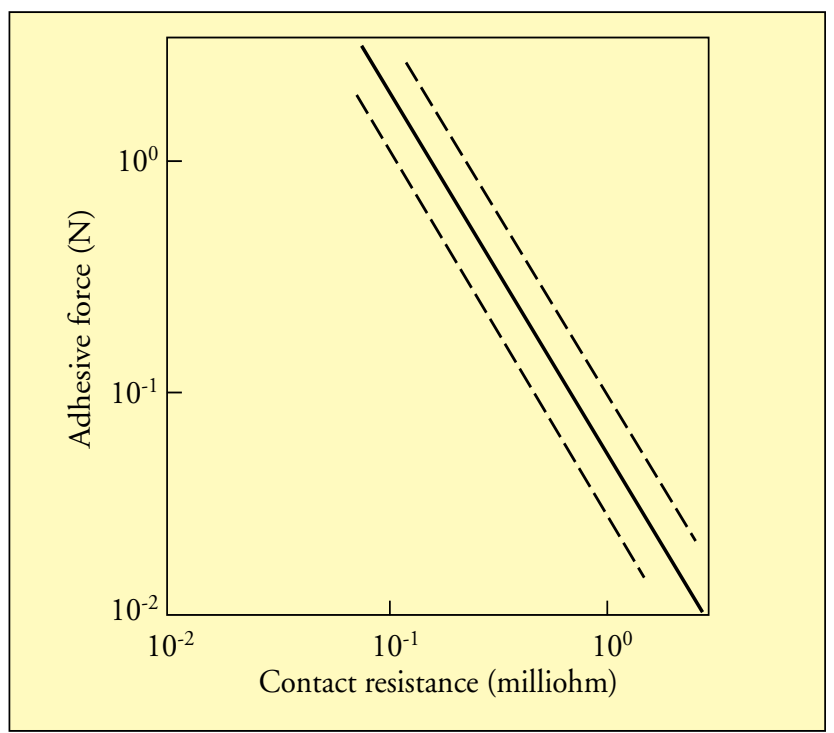

Figure 6 Relationship between adhesive force and contact resistance between hard gold films (Data taken from reference 60) (Solid line drawn through median of data points taken at contact forces of $0.1 \mathrm{~N}, 0.2 \mathrm{~N}$, and $0.5 \mathrm{~N}$ scattered between broken lines) load. On the other hand, the wear resistance of AFHG is very poor compared to that of CoHG unless a suitable lubricant is applied (6). The data obtained by Antler (56) show that the dimensionless wear index of a 0.75 micrometer thick AFHG rose to as high as 95 after less than 20 sliding cycles performed at a load of $100 \mathrm{~g}$, whereas for $\mathrm{CoHG}$ it took 100 cycles to reach this level of wear under identical conditions. It should be noted that the hardness of AFHG $(180 \pm 20 \mathrm{~kg}$ $\mathrm{mm}^{-2}$ in Knoop hardness) is nearly equal to that of CoHG $\left(170 \pm 30 \mathrm{~kg} \mathrm{~mm}^{-2}\right)$, and the grain sizes of the two types of hard gold are similar $(25 \pm 2.5 \mathrm{~nm}$ for CoHG and 25 to $75 \mathrm{~nm}$ for AFHG) (7). Obviously, hardness or grain size by itself does not determine wear resistance.

Two bulk properties have been proposed in the literature to be relevant to wear resistance: ductility (57) and internal stress (58). Antler (57) noted that AFHG has a ductility of $2-3 \%$ in terms of percentage elongation as compared to less than $0.4 \%$ for CoHG. The high ductility was thought to promote adhesion between sliding surfaces, causing "adhesive wear" as opposed to "abrasive wear". However, Abys et al (59) recently reported that palladium alloys, eg, $\mathrm{PdNi}$ and PdCo, possess ductilities as high as 3 to $10 \%$, and yet they are 2 to 5 times more wear resistant than hard gold. Clearly, ductility alone does not determine wear resistance. On the other hand, the relevance of internal stress to wear resistance was pointed out by Celis et al (58). They found that the internal stress of CoHG varies as a function of metallic Co content, and noted that wear resistant deposits were obtained at the metallic Co content in the range of 0.05 to $0.1 \mathrm{wt} \%$, where the internal stress ranged from 100 to $250 \mathrm{~N}$ $\mathrm{mm}^{-2}$. When the metallic Co content was too low, internal stress was also too low, and adhesive wear resulted. When the metallic Co content was too high, internal stress became too high, causing abrasive wear. This empirical relationship is of interest, but no mechanistic interpretation has been offered. From the practical viewpoint, it is important to be aware of the finding of De Donker and Vanhumbeeck (53) that wear resistant deposits can be obtained only when the ratio of $\mathrm{CN}$-complexed $\mathrm{Co}$ to metallic Co was greater than unity. Apparently, the inclusion of the complexed cobalt plays an important role in determining wear resistance.

Nickel-hardened gold has not been investigated nearly as extensively as CoHG for the effect of inclusions on physical properties. It is known, however, that NiHG contains equally significant quantities of various non-metallic elements in addition to $\mathrm{Ni}(37)$, 
and it can be expected that inclusions play an equally important role in determining physical properties of $\mathrm{NiHG}$ as in the case of CoHG. Clearly, without detailed knowledge on inclusion effects such as that reported by De Donker and Vanhumbeeck (53) for the case of CoHG, different types of hard gold should not be compared indiscriminately for wear resistance and other physical properties of practical importance.

\section{(iii) Sticking of Relay Contacts}

Miniature relays with contact surfaces plated with hard gold are known to fail occasionally due to sticking after a certain number of operating cycles. The phenomenon of sticking is believed to be related to the adhesive wear of sliding connector contacts described in the preceding section, although the sliding distance of the relay contacts is only a very small fraction of that of connectors. To understand factors causing the sticking between a pair of contact surfaces, it is useful to measure the force of adhesion as a function of variables such as the load applied to contact surfaces, the sliding distance, the number of open-closure cycles, and most importantly the composition of gold layers both in the bulk and at the surface.

Kobayashi et al (60) carried out a detailed study of the phenomenon of adhesion of gold contact surfaces. They showed that initially the adhesive force increases with the number of sliding cycles, reaching a constant value after a certain number of sliding cycles, and that it increases with increasing contact force. Another significant finding was that adhesive force decreases with increasing electrical contact resistance. A loglinear relationship exists between the two parameters, as reproduced in a simplified fashion in Figure 6. This relationship is understandable if it is assumed that the increase in contact resistance is due to the presence of non-conducting materials on the gold surface, because when the surfaces are contaminated with such materials, the tendency of adhesion is expected to decrease. The contamination is believed to result from surface segregation of inclusions existing in the bulk of the gold. From a practical standpoint, the presence of surface contaminants is beneficial for minimizing the tendency to stick, but it is undesirable because it increases contact resistance. Therefore, for optimum performance of relay contacts, a compromise must be made between the tendency of sticking and the magnitude of contact resistance. These authors did not describe the kind and composition of the gold they employed to obtain the data. A study of this aspect should provide important information on materials selection for the fabrication of relay contacts.

\section{CONCLUSIONS}

The significance of both metallic and non-metallic inclusions on the physical properties of electroplated gold films has been discussed by critically reviewing both old and new data published in the literature. The origins of carbon and sulfur in soft gold deposits plated, respectively, from the classical cyanide bath and the thiosulfate-sulfite mixed ligand bath are most likely to be $\mathrm{AuCN}$ and $\mathrm{Au}_{2} \mathrm{~S}_{2} \mathrm{O}_{3}$, both of which are adsorbed on individual gold crystals and trapped in the gold films. These inclusions adversely affect the hardness of the films. The inclusion of an excessive amount of the so-called grain-refining metals such as $\mathrm{Pb}, \mathrm{Tl}$, and As is also detrimental for obtaining acceptable bond strength when gold or aluminium wire is bonded to the soft gold film plated in a bath containing one of those additives. Thus, soft gold represents the case where the presence of either metallic or non-metallic inclusion is detrimental.

On the other hand, one of the desirable properties of hard gold, ie the high resistance to wear, is obtained via the presence of inclusions. It should be realized, however, that as in the case of cobalt-hardened gold, acceptable wear resistance can be obtained only when included substances, $i e$, metallic $\mathrm{Co}$ and $\mathrm{CN}$-complexed $\mathrm{Co}$, are present at concentrations within specific limits and at a ratio greater than a specific value. No such details are known for nickelhardened gold, but it is most likely that similar concentration limits exist. Thus, indiscriminate comparison of different kinds of hard gold for specific properties should not be made without a detailed knowledge of inclusion effects for each type of the golds to be compared.

It is hoped that this review article will convince the reader of the importance of the role played by inclusions in determining both bulk and surface properties of electroplated gold films for electronics applications. There are still several unresolved issues concerning identification of included substances and their significance in determining deposit properties. For example, a relatively large amount of potassium is incorporated in both $\mathrm{CoHG}$ and AFHG (Table 3), but the significance of inclusion of this element is not well understood and hence not discussed in this review. Further work is needed to obtain a better understanding of these unresolved issues.

\section{ABOUT THE AUTHOR}

Yutaka Okinaka, a Fellow of the Electrochemical Society, is a former Distinguished Member of Technical Staff at AT\&T Bell Laboratories, now Lucent Technologies, Murray Hill, New Jersey, USA. 
After retirement from Bell Labs in 1990, Dr Okinaka became a Visiting Professor at Waseda University, Tokyo, Japan until 1996, where he still actively directs research in the field of gold plating for electronics as a Visiting Research Fellow.

\section{REFERENCES}

1 W.H. Safranek, 'The Properties of Electrodeposited Metals and Alloys', Second Edition, American Electroplaters and Surface Finishers Society, Orlando, Florida, 1986

2 H.A. Reinheimer, J. Electrochem. Soc., 1974, 121, 490

3 T. Osaka, A. Kodera, T. Misato, T. Homma, Y. Okinaka and O. Yoshioka, J. Electrochem. Soc., 1997, 144, 3462

4 'Gold Plating Technology”, ed. F.H. Reid and W. Goldie, Electrochemical Publications, Ltd., Ayr, Scotland, 1974

5 W.S. Rapson and T. Groenewald, 'Gold Usage', Academic Press, London, 1978

6 F.B. Koch, Y. Okinaka, C. Wolowodiuk and D.R. Blessington, Plating, 1980, 67(6), 50; 1980, 67(7), 43

7 Y. Okinaka and F.B. Koch, 'Proceedings of the 10th World Congress on Metal Finishing (Interfinish 80)', 1980, pp.48-52

8 D.M. MacArthur, J. Electrochem. Soc., 1972, 119, 672

9 J.D.E. McIntyre and W.F. Peck, Jr., J. Electrochem. Soc., 1976, 123, 1800

10 E.T. Eisenmann, J. Electrochem. Soc., 1978, 125, 717

11 S. Nakahara and Y. Okinaka, J. Electrochem. Soc., 1981, 128, 284

12 G. Holmbom and B.E. Jacobson, J. Electrochem. Soc., 1988, 135, 787

13 T. Sawaguchi, T. Yamada, Y. Okinaka and K. Itaya, J. Phys. Chem., 1995, 99, 14149

14 R. Duva and A. Simonian, US Patent 3,562,120, 1971

15 H.A. Reinheimer, US Patent 3,833,487, 1974

16 L. Greenspan, US Patent 3,423,295, 1969

17 R. Zimmerman and R. Brenneman, British Patent 1,275,386, 1972

18 S.T. Rao and R. Weil, Metal Finishing, 1979, 57, 97

19 T.E. Dinon and H.Y. Cheh, J. Electrochem. Soc., 1992, 139, 410

20 D.W. Endicott, H.K. James and F. Nobel, Plating and Surface Finish.,1981, 68(11), 58

21 S. Wakabayashi, A. Murata and N. Wakabayashi, Plating and Surface Finish., 1982, 69(8), 63

22 S. Wakabayashi, K. Harayama, S. Iwai and M. Nakazawa, Kinzoku Hyomen Gijutsu (J. Metal Finish. Soc. Japan), 1988, 39, 189

23 A. Chinda and O. Yoshioka, Kinzoku Hyomen Gijutsu (J. Metal Finish. Soc. Japan), 1988, 39, 210

24 Y. Okinaka, 'Proceedings of the Symposium on Electrodeposition Technology - Theory and Practice', ed. L.T. Romankiw and D.R. Turner, The Electrochemical Society, Inc., 1987, 87-17, 147

25 Y. Okinaka, in 'Precious Metals - Modern Technologies and Applications (EAST Report 1991)', European Academy of Surface Technology, Schwäbisch Gmünd, Germany, 1991, pp. 8-18

26 P.A. Kohl, in 'Modern Electroplating, Fourth Edition', ed. M. Schlesinger and M. Paunovic, John Wiley and Sons, Inc., 2000, pp. 201-225

27 J. Ushio, O. Miyazawa, H. Yokono and A. Tomizawa, US Patent 4,804,559, 1989

28 T. Inoue, S. Ando, H. Okudaira, J. Ushio, A. Tomizawa, H. Takehara, T. Shimazaki, H. Yamamoto and H. Yokono, 'Proceedings of the 45th IEEE Electronic Components Technology Conference', 1995, p.1059
29 M. Kato, K. Niikura, S. Hoshino and I. Ohno, Hyomen Gijutsu (J. Surface Finish. Soc. Japan), 1991, 42, 729

30 M. Kato, Y. Yazawa and Y. Okinaka, 'Proceedings of AESF Technical Conference, SUR/FIN 95', American Electroplaters and Surface Finishers Society, 1995, pp. $805-$ 813

31 K. Yoshizawa, J. Sato, M. Kato, T. Misato, T. Homma, Y. Okinaka, O. Yoshioka and T. Osaka, Extended Abstract of the Paper Presented at the 101st Technical Conference of the Surface Finishing Society of Japan, 2000, Paper 23D-10

32 X. Wang, N. Issaev and J.G. Osteryoung, J. Electrochem. Soc., 1998, 145, 974

33 S. Nakahara, Lucent Technologies, Private communication, 1999

34 C.C. Lo, J.A. Augis and M.R. Pinnel, J. Appl. Phys., 1979, 50, 6887

35 Y. Okinaka and S. Nakahara, J. Electrochem. Soc., 1976, 123, 1284

36 G.B. Munier, Plating, 1969, 56, 1159

37 Ch.J. Raub, A. Knödler and J. Lendvey, Plating, 1976, 63, 35

38 Y. Okinaka, F.B. Koch, C. Wolowodiuk and D.R. Blessington, J. Electrochem. Soc,, $1978,125,1745$

39 B.M. Chadwick and A.G. Sharpe, in Advances in Inorganic Chemistry and Radiochemistry', Vol 8, 1966, pp.83-176

40 D. Kahn, 'Proceedings of AESF Technical Conference, SUR/FIN 92', 1992, p.305

41 S. Nakahara and Y. Okinaka, in 'Properties of Electrodeposits - Their Measurements and Significance', ed. R. Sard, H. Leidheiser, and F. Ogburn, The Electrochemical Society, Inc., 1975, pp.50-62

42 W. Fluehmann, F.H. Reid, R.A. Mausli and S.G. Steinemann, Plating and Surface Finish., 1980, 67(6), 62

43 S. Nakahara, J. Electrochem. Soc., 1989, 136, 451

44 P.K. Gallagher, Thermochim. Acta, 1980, 41, 323

45 Ch.J. Raub, Plating and Surface Finish., 1993, 80(9), 30

46 B. Bozzini, G. Giovanelli, S. Natali, B. Brevaglieri, P.L. Cavallotti and G. Signorelli, Engineering Failure Analysis, 1998, 6, 83

47 P.L. Cavallotti, Private Communication, 1999.

48 Y. Okinaka and T. Homma, 'Proceedings of the Third International Symposium on Electrochemical Technology Applications in Electronics', ed. L.T. Romankiw, T. Osaka, Y. Yamazaki and C. Madore, The Electrochemical Society, Inc., 1999, 99-34, 132

49 J.E. Graebner and Y. Okinaka, J. Appl. Phys., 1986, 60(1), 36

50 Ch.J. Raub, Private Communication, 1992

51 Y. Okinaka and M. Hoshino, Gold Bull., 1998, 31(1), 3

52 J.H. Thomas and S.P. Sharma, J. Electrochem. Soc., 1979, 126, 445

53 R. DeDonker and J. Vanhumbeeck, Trans. Inst. Met. Finish., 1985, 62(2), 59

54 M. Huck, Metallwiss. u. Technik, 1992, 46, 132

55 M. Antler, Plating and Surface Finish., 1998, 85(12), 85

56 M. Antler, Private Communication, 1989

57 M. Antler, IEEE Transactions on Components, Hybrids, and Manufacturing Technology, CHMT-4, No.1, 15 (1981)

58 J.P. Celis, J.R. Roos, W. Van Vooren and J. Vanhumbeeck, Trans. Inst. Met. Finish., $1989,67,70$

59 J.A. Abys, G.F. Breck, H.K. Straschil, I. Boguslavsky and G. Holmbom, Plating and Surface Finish., 1999, 86(1), 108

60 A. Kobayashi, S. Takano and T. Kubono, Technical Reports of IEICE, 1995, EMD 95-57 